La Junta

REVISTA DE INNOVACIÓN E INVESTIGACIÓN CONTABLE

\title{
Palabras del presidente
}

En esta primera edición del año 2021 de la Revista Institucional LA JUNTA, quiero agradecer a todos los colegas y amigos que con sus artículos académicos hicieron posible que llegue a ustedes esta publicación, la cual poco a poco se va convirtiendo en una de las favoritas de los profesionales de Contabilidad y todos los que estamos comprometidos con el desarrollo empresarial y de las instituciones gubernamentales. Este esfuerzo meritorio lo valoramos mucho más, al darse en un contexto tan difícil para el mundo y el país en su totalidad.

En esta edición tenemos temas de mucha actualidad en educación universitaria que nos dan las herramientas necesarias para mejorar la didáctica y evaluación del aprendizaje en un entorno virtual. También tratamos temas sobre las contrataciones del Estado y sus posibles riesgos en sus procesos, evaluados desde el control interno, así como el proceso de planificación de los actos preparatorios de las contrataciones del Estado.

Resaltamos también la inclusión en esta edición de la ética profesional en procesos de controversias en nuestro país, las cuales han sido muy criticadas por la parcialización en sus resultados. Finalmente, el confinamiento que nos ha obligado la pandemia COVID-19 ha dañado seriamente la economía del país, empresas y personas. Es por eso que Víctor Puican nos presenta su investigación sobre la quiebra de las economías familiares en tiempos de confinamiento.

La Junta de Decanos sigue realizando sus actividades en un entorno virtual - sesiones, capacitaciones, eventos nacionales hasta que el gobierno levante las medidas de confinamiento. Adicional a estas 
medidas, el país atraviesa por una incertidumbre política debido a la falta de resultados oficiales, de las elecciones generales para el cambio de presidente, resultados que debería emitir el Jurado Nacional de Elecciones. Mientras tanto, nuestra economía como país se encuentra presenta una inestabilidad preocupante. Esperemos que la nueva gestión que asuma este 28 de julio tome decisiones a la altura de los problemas que nos aquejan en este año del Bicentenario.

En este primer semestre del 2021, la Junta de Decanos ha aprobado el proyecto de "Transformación Digital de la Profesión Contable en el Perú". Con este plan aspiramos a modernizar nuestros procesos administrativos, académicos y de gestión, el cual nos permita tener información oportuna y confiable. También contamos con un cronograma aprobado que nos permitirá en el mediano plazo, implementar en nuestro país el cumplimiento de las versiones vigentes de las normas de ética, auditoría, educación, investigación, NIIF y NIC para el Sector Público, normas dictadas por IFAC.

Estimados colegas y amigos, el panorama político y económico no es muy favorable para el país, pero confiamos en la creatividad y el profesionalismo para revertir esta situación, y construir un mejor país para nuestros hijos, un país donde prime el respeto, solidaridad y justicia.

Felices fiestas patrias y feliz Bicentenario.

\section{Rogelio Regalado Villegas \\ Presidente de la Junta de Decanos de Colegios de Contadores Públicos del Perú}

